\title{
Dispensing Small Droplets with Low Generating Power
}

\author{
Geon Hwee Kim¹, Jung Hwal Shin ${ }^{1,2}$, Taechang $\mathrm{An}^{3}$, \\ Intae $\mathrm{Kim}^{1}$ and Geunbae $\mathrm{Lim}^{1, *}$ \\ 'Department of Mechanical Engineering, Pohang University of Science and Technology (POSTECH), \\ Pohang 790-784, Republic of Korea \\ ${ }^{2}$ Center for Cognition and Sociality, Institute for Basic Science (IBS), \\ Daejeon 305-811, Republic of Korea \\ ${ }^{3}$ Department of Mechanical Design Engineering, Andong National University, \\ Andong 760-749, Republic of Korea
}

(Received July 17, 2014; accepted December 8, 2014)

Key words: carbon nanotube nanobundle, electrospray, low power, bioapplication

Dispensed small droplets are widely used in analyses of small organisms in various bioapplications. The generating power used to induce "flying beads" of dispensed small droplets should be sufficiently low to guarantee the safety of the organisms. In this study, we fabricated carbon nanotube (CNT) nanobundles electroplated with gold nanoparticles. Small droplets were generated by the repulsive force in an ion-concentrated zone; in this region, the droplets were generated at lower voltages due to the higher ion concentration. The generating power was examined as a function of electrode diameter $(0.6,20$, and $500 \mu \mathrm{m})$ and decreased significantly with electrode size, specifically $0.007 \mathrm{~mW}$ for the 0.6- $\mu \mathrm{m}$-diameter electrode compared with $0.017 \mathrm{~W}$ for the $20-\mu \mathrm{m}$-diameter electrode. The beads expelled from the mother droplet at $0.007 \mathrm{~mW}$ had an initial velocity of $\sim 2 \mathrm{~m}$ $\min ^{-1}$. This technique is expected to be particularly useful for the analysis of very small analytes.

\section{Introduction}

Small-volume dispensed droplet generators have been developed recently by several research groups. ${ }^{(1-6)}$ Stationary liquid microjets, for example, dispense droplets by inducing fluid interface instabilities. Nanoscale dispensing of fluids has been demonstrated using atomic force microscopy (AFM) probes via the aperture in their apex. The small droplets formed by electric fields are used for patterning, particle trapping, and liquid microlenses.

Electrohydrodynamic atomization (EHDA) is a technique that uses electrostatic force to generate small droplets (on the order of $1 \mathrm{~nm}$ up to several microns in size). ${ }^{(7-10)} \mathrm{In}$

*Corresponding author: e-mail: limmems@postech.ac.kr 
this technique, a metal tube is filled with a conducting liquid, and the tube is maintained at a high potential with respect to a ground electrode. At the outlet of the tube, the liquid forms a conical meniscus that gathers counterions, thus creating a high charge density at the meniscus tip. When the charge repulsive force exceeds the local surface tension, a small droplet is expelled from the meniscus.

Small droplets are widely used in microfluidic systems for single-cell analysis, ${ }^{(1-14)}$ complex multistep biological and chemical assays, ${ }^{(15-17)}$ diagnostics, ${ }^{(18-20)}$ and directed evolution experiments. ${ }^{(21,22)}$ Extraction of the analytical sample from carrier oils, a common practice, is more difficult than the EHDA technique. However, the EHDA technique has limited applicability to biological systems, owing to the high current produced as a result of the high potential required. To guarantee the safety of organisms, the potential and current should be as low as possible. Thus, small-scale electrodes are needed to concentrate the electric field. ${ }^{(23)}$

Carbon nanotubes (CNTs) are being used increasingly for nanoscale electrode fabrication. ${ }^{(24,25)}$ Nanoscale electrodes with submicron dimensions have been developed as individual nanoelectrodes, ${ }^{(26,27)}$ nanoelectrode arrays, and nanoelectrode ensembles. ${ }^{(28,29)}$ The EHDA technique requires individual nanoelectrodes.

In this study, we fabricated individual nanoelectrodes using CNTs. The "flying beads" phenomenon was assessed by current analysis, and the size of the beads was investigated by scanning electron microscopy (SEM). The generating voltage and power of the small droplets depended on the ion concentration of the ionic solution and the diameter of the electrode, respectively. Our results demonstrate the advantages of using CNT nanobundles for dispensing small droplets, a technique that can be applied readily to biological studies.

\section{Materials and Methods}

\subsection{Dispersion of CNTS}

Single-walled nanotubes (SWNTs) (length, 5-20 $\mu \mathrm{m}$; diameter, 1.0-1.2 nm) were produced using an arc discharge process (Hanhwa Nanotech, Incheon, South Korea). Oxidization in a strong acid with sonication produced SWNT-COOH. First, SWNTs (10 mg) were mixed in $50 \mathrm{~mL}$ of $\mathrm{H}_{2} \mathrm{SO}_{4} / \mathrm{HNO}_{3}(3: 1, \mathrm{v} / \mathrm{v})$ solution and sonicated in an ultrasonic bath for $3 \mathrm{~h}$. The SWNT suspension was diluted with deionized (DI) water; the remaining acid was completely removed by decanting the supernatant and repeatedly washing it with DI water. When the $\mathrm{pH}$ of the suspension reached 7.4, the SWNTs were redispersed in DI water with sonication for $5 \mathrm{~min}$.

\subsection{Fabrication of CNT nanobundle}

Tungsten tips with ends approximately $5 \mu \mathrm{m}$ in diameter were fabricated by electrolysis [2-M NaOH; direct current (DC) voltage, $-7 \mathrm{~V}$ ]. Figure 1(a) shows a sharpened tungsten tip placed a few microns from a tube containing the CNT suspension. Each tungsten tip was submerged in the CNT solution up to the desired position, and an alternating current (AC) electric field (frequency, $1 \mathrm{MHz}$; amplitude, $5 \mathrm{~V}$ peak-to-peak) was applied between the tip and tube [Fig. 1(b)]. 


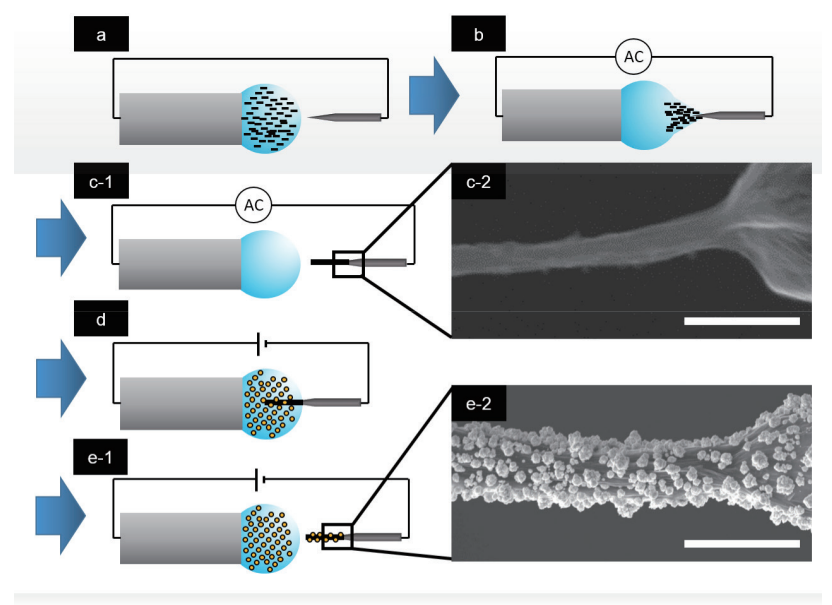

Fig. 1. (Color online) Fabrication of a CNT nanobundle. (a) CNT suspended solution in a syringe. (b) An AC electric field was applied and surface tension compressed the CNTs near the tungsten electrode. (c) Fabricated CNT nanobundle (scale bar, $1 \mu \mathrm{m}$ ). (d) and (e) Gold nanoparticle electroplating (scale bar, $1 \mu \mathrm{m}$ ).

CNTs gathered at the apex of the tungsten electrode, owing to the dielectrophoretic (DEP) force. The droplet was partially removed, leaving the remaining droplet to form a water meniscus between the tungsten tip and the solution. The gathered CNTs were compressed by the surface tension and became attached to the tungsten tip. As a result, a CNT nanobundle formed on the tungsten tip [Fig. 1(c)]. Gold nanoparticles coated the CNT nanobundle surface by electrodeposition; the gold coating increased the binding force of the CNT nanobundle [Fig. 1(d)]. A DC voltage of $-1 \mathrm{~V}$ was applied to the CNT nanonbundle in a solution containing 1 to $5 \mathrm{mM} \mathrm{HAuCl}_{4} \cdot 4 \mathrm{H}_{2} \mathrm{O}$ and $500-\mathrm{mM} \mathrm{HBO}_{3}$.

\subsection{Experimental setup}

The experimental setup consisted of an ionic solution, CNT nanobundles, a collecting substrate, a gold electrode, and a humidity chamber. A power supply was used for DC voltage application between the two electrodes (CNT nanobundle and gold electrode), while an ammeter measured the current simultaneously [Fig. 2(a)]. The gold electrode was placed in a humidity chamber. An ionic solution droplet (volume, $2 \mu \mathrm{L}$ ) was placed on the gold electrode; a wet tissue prevented the evaporation of the mother droplet and flying beads. The humidity chamber was maintained at $>85 \%$ relative humidity $[\mathrm{RH}$; Fig. 2(b)]. The humidity chamber and CNT nanobundle were connected to three-axis stages, operated independently for precise control over the electrode position.

\subsection{Current measurement}

The current response of the electrode was measured using a two-electrode cell configuration (Modulab System, Solartron Instruments, Elmsford, NY, USA) consisting of the gold electrode and CNT nanobundle. The applied voltage was swept over a 

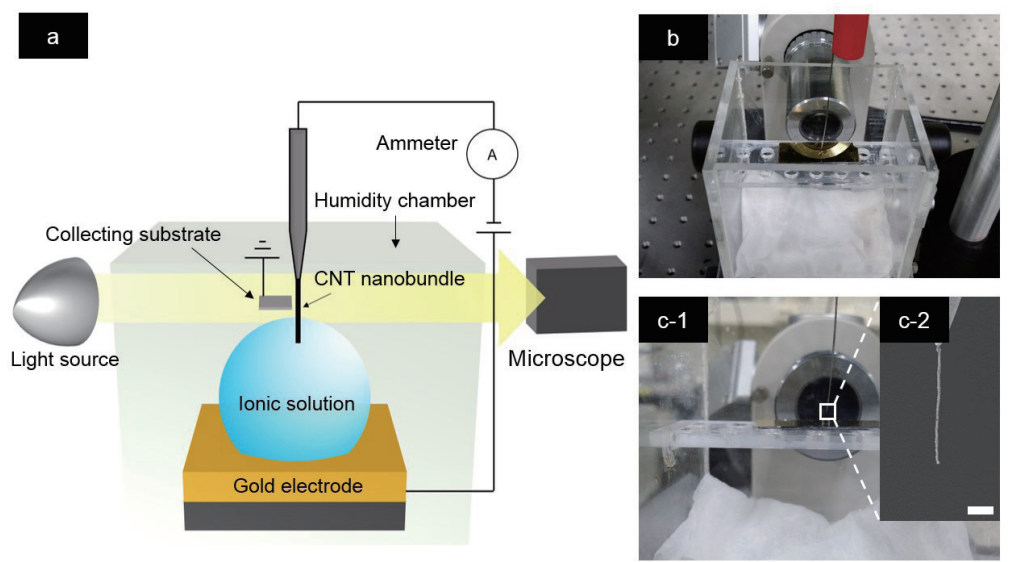

Fig. 2. (Color online) Experimental setup. (a) Schematic diagram of the experimental setup: (b) top and (c) side views of the system setup (scale bar, $5 \mu \mathrm{m}$ ).

range of -5 to $0 \mathrm{~V}$ (scan rate: $100 \mathrm{mV} \mathrm{s}^{-1}$ ), beginning with the open-circuit potential and sweeping in a negative direction.

\subsection{High-speed camera analysis}

The motion of the flying beads was observed using a high-speed camera. Images were taken with a shutter speed of $1 / 40000 \mathrm{~s}$. The droplet displacement and velocity were calculated by the pixel analysis of images captured sequentially [Fig. 3(c)]. The velocity of droplets was calculated by dividing the displacement by the time gap of the images.

\section{Results and Discussion}

\subsection{Fabrication of the CNT nanobundle}

Small droplets have been used in various bioapplications. However, the EHDA technique uses high electric fields that could potentially damage biological samples. Thus, in this study, small electrodes were used to lower the potential and current by concentrating the electric field.

The CNT nanobundle diameter could be controlled by changing the morphology of the tungsten tip, the applied voltage, and the applied frequency. To fabricate smaller CNT nanobundles, the tungsten tip should have a sharper morphology. Figure 1(c) shows an example of the tip structure and the resulting CNT nanobundle (diameter, 400 $\mathrm{nm})$.

\subsection{Flying bead phenomenon}

When a voltage was applied between the two electrodes, small droplets were expelled from the mother droplet over a certain voltage range. In this process, the applied voltage 

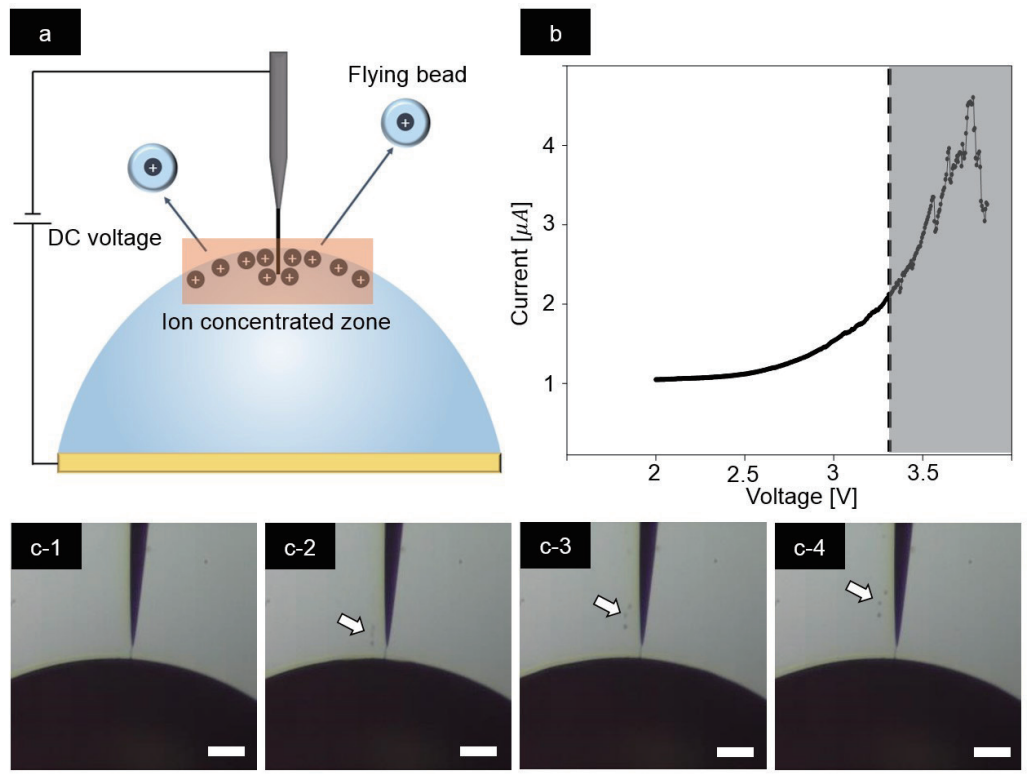

Fig. 3. (Color online) Flying bead phenomenon. (a) Schematic image of a flying bead. The red box indicates the ion-concentrated zone. (b) Current-voltage curve. The gray box indicates the domain of the flying bead phenomenon (scan rate, $100 \mathrm{mV} \mathrm{s}^{-1} ; \mathrm{KCl}$ concentration, $50 \mathrm{mM}$ ). (c) Time-lapse images of flying beads using a high-speed camera. Arrows indicate the positions of flying beads (shutter speed, 1/40000 s; scale bar, $50 \mu \mathrm{m}$ ).

induced counter-ion formation at the CNT nanobundle in the ionic solution [Fig. 3(a)]. The ion concentration near the CNT nanobundle gradually increased over time, because the small CNT nanobundle could not provide a sufficient oxidation response. Thus, the ionic concentration close to the CNT nanobundle was much higher. When the repulsive force between the gathered ions became greater than the surface tension force of the mother droplet, small droplets/beads were expelled from the mother droplet.

The current between the CNT nanobundle and the gold electrode was measured during the voltage sweep [Fig. 3(b)]. The current gradually increased with the voltage to a certain point before becoming unstable (i.e., the development of current fluctuations), resulting in small droplet/bead generation. The unstable current implies an unstable redox response with respect to the electrode. These results indicate that the small droplets were generated by the repulsive force in the ion-concentrated zone close to the electrode.

A high-speed camera was used to study the motion and speed of the flying droplets/ beads [Fig. 3(c)]. The beads generated close to the CNT nanobundle [Fig. 3(c-2)] and the expelled beads flew vertically at high speeds. The initial velocity of the flying beads was $\sim 3 \mathrm{~cm} \mathrm{~s}^{-1}$; the velocity of the beads gradually decreased over time [Figs. 3(c-3) and 3(c4)]. 


\subsection{Generating voltages of the flying beads}

Current-voltage $(I-V)$ plots [Fig. 4(a)] were used to study the generating voltage of the flying beads as a function of the $\mathrm{KCl}$ concentration. $\mathrm{KCl}$ was adopted as the ionic solution because the $\mathrm{K}+$ and $\mathrm{Cl}^{-}$ions have the same mobility. In this experiment, $\mathrm{KCl}$ concentrations were $0,0.5$, and $1 \mathrm{M}$, and the generating voltages were $5.6,4$, and 3.3 $\mathrm{V}$, respectively [Fig. 4(a)]. As the $\mathrm{KCl}$ solution concentration increased, the generating voltage decreased significantly $(p=0.00018, p=0.007)$. This result suggests that the flying bead phenomenon was affected by the ion concentration of the solution. The flying beads were generated by the repulsive force in the ion-concentrated zone; thus, in this region, the flying beads could be generated at lower voltages due to the higher ion concentration.

\subsection{Generating power of flying beads}

As mentioned above, bioapplications require low generating power and voltage to ensure the safety of the organisms. Three electrodes of various diameters $(0.6,20$, and $500 \mu \mathrm{m}$ ) were used in this experiment. Figure 4(b) shows the generating power for each electrode; the figure inset shows the generating power using $0.6-$ and $20-\mu \mathrm{m}$ diameter electrodes. The generating power decreased significantly with electrode size. Specifically, the generating power of $0.007 \mathrm{~mW}$ for the $0.6-\mu \mathrm{m}$-diameter electrode was
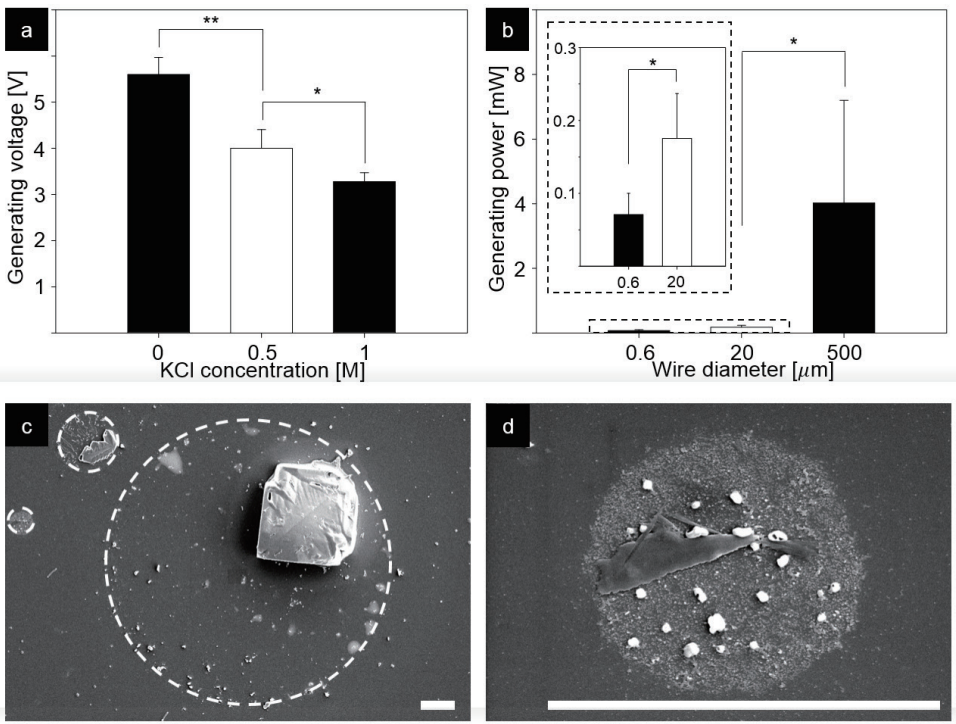

Fig. 4. Generating voltages and powers of flying beads. (a) Flying-bead generating voltages by $\mathrm{KCl}$ concentrations. (b) Flying-bead generating powers by wire diameters. Values were analyzed using t-test; mean \pm standard deviation, $n=5,{ }^{*} p<0.05,{ }^{* *} p<0.001$. (c) SEM images of the collected beads analyzed using the coffee ring effect. (d) SEM image of the smallest bead (scale bar: $10 \mu \mathrm{m})$. 
significantly lower than that for the 20 - $\mu \mathrm{m}$-diameter electrode (power, $0.017 \mathrm{~mW}$ ). The 500- $\mu \mathrm{m}$-diameter electrode generated $\sim 600$ times more power than the $0.6-\mu \mathrm{m}$ diameter electrode. Thus, CNT nanobundles are advantageous over microelectrodes in bioapplications, owing to their low generating power.

\subsection{Analysis of bead size}

A silicon wafer was placed close to the CNT nanobundle to collect dispensed beads from the mother droplet using inertia and Coulombic attraction. The flying beads generated by the CNT nanobundle were observed using an optical microscope. The diameter of the flying beads was several hundreds of nanometers. The flying beads generated by the $500-\mu \mathrm{m}$-diameter electrode were collected by the collecting substrate. The voltage was swept to collect beads with various sizes [Fig. 4(c)], and the sizes of the collected beads were calculated using the coffee ring effect. Figure 4(d) shows that the diameter of the smallest bead was $\sim 7 \mu \mathrm{m}$ and its volume was $\sim 700 \mathrm{fl}$. oz. In future research, bead sizes will be analyzed using a more precise collection system.

\section{Conclusions}

CNT nanobundles electroplated with gold nanoparticles were fabricated to create a small droplet dispenser. Small droplets or flying beads were generated when the repulsive force between the gathered ions was greater than the surface tension force. The current created between two electrodes expelled the flying beads from the ionconcentrated zone close to the electrode. The beads were ejected from the mother droplet at a high velocity $\left(2 \mathrm{~m} \mathrm{~min}^{-1}\right)$, and the velocity gradually decreased over time. The generating voltage was influenced by the ion concentration of the solution and was lower for higher ion concentrations. The generating power was affected by the electrode diameter and was lower for smaller diameter electrodes. This CNT nanobundle droplet dispenser can potentially be used in bioapplications involving very small organisms, owing to the low generating voltage and power used.

\section{Acknowledgements}

This work was supported by the National Research Foundation of Korea (NRF) grant funded by the Korean government (MEST) (No. 2012R1A1A2007580), the Industrial Technology Innovation Program (No. 10048358) funded by the Ministry of Trade, Industry and Energy (MI, Korea), and the NRF grant funded by the Korean government (MSIP) (No. 2011-0030075).

\section{References}

1 L. Mazutis, J. Gilbert, W. L. Ung, D. A. Weitz, A. D. Griffiths and J. A. Heyman: Nat. Protoc. 8 (2013) 870.

2 A. Casner and J.-P. Delville: Phys. Rev. Lett. 90 (2003) 144503.

3 B. de Heij, M. Daub, O. Gutmann, R. Niekrawietz, H. Sandmaier and R. Zengerle: Anal. Bioanal. Chem. 378 (2004) 119. 
4 J. Y. Huang, Y.-C. Lo, J. J. Niu, A. Kushima, X. Qian, L. Zhong, S. X. Mao and J. Li: Nat. Nanotechnol. 8 (2013) 277.

5 S. Grilli and P. Ferraro: Appl. Phys. Lett. 92 (2008) 232902.

6 L. Miccio, A. Finizio, S. Grilli, V. Vespini, M. Paturzo, S. De Nicola and P. Ferraro: Opt. Express. 17 (2009) 2487.

7 R. T. Collins, J. J. Jones, M. T. Harris and O. A. Basaran: Nat. Phys. 4 (2008) 149.

8 T. Achtzehn, R. Müller, D. Duft and T. Leisner: Eur. Phys. J. -At. Mol. Opt. Plasma Phys. 34 (2005) 311.

9 J. B. Fenn, M. Mann, C. K. Meng, S. F. Wong and C. M. Whitehouse: Science 246 (1989) 64.

10 K. J. Ptasinski and P. J. A. M. Kerkhof: Sep. Sci. Technol. 27 (1992) 995.

11 M. He, J. S. Edgar, G. D. M. Jeffries, R. M. Lorenz, J. P. Shelby and D. T. Chiu: Anal. Chem. 77 (2005) 1539.

12 J. Clausell-Tormos, D. Lieber, J.-C. Baret, A. El-Harrak, O. J. Miller, L. Frenz, J. Blouwolff, K. J. Humphry, S. Köster, H. Duan, C. Holtze, D. A. Weitz, A. D. Griffiths and C. A. Merten: Chem. Biol. 15 (2008) 427.

13 E. Brouzes, M. Medkova, N. Savenelli, D. Marran, M. Twardowski, J. B. Hutchison, J. M. Rothberg, D. R. Link, N. Perrimon and M. L. Samuels: Proc. Natl. Acad. Sci. 106 (2009) 14195.

14 H. Hufnagel, A. Huebner, C. Gülch, K. Güse, C. Abell and F. Hollfelder: Lab. Chip. 9 (2009) 1576.

15 L. Mazutis, A. F. Araghi, O. J. Miller, J.-C. Baret, L. Frenz, A. Janoshazi, V. Taly, B. J. Miller, J. B. Hutchison, D. Link, A. D. Griffiths and M. Ryckelynck: Anal. Chem. 81 (2009) 4813.

16 D. Chen, W. Du, Y. Liu, W. Liu, A. Kuznetsov, F. E. Mendez, L. H. Philipson and R. F. Ismagilov: Proc. Natl. Acad. Sci. 105 (2008) 16843.

17 L. Mazutis, J.-C. Baret, P. Treacy, Y. Skhiri, A. F. Araghi, M. Ryckelynck, V. Taly and A. D. Griffiths: Lab. Chip. 9 (2009) 2902.

18 D. Pekin, Y. Skhiri, J.-C. Baret, D. Le Corre, L. Mazutis, C. B. Salem, F. Millot, A. El Harrak, J. B. Hutchison, J. W. Larson, D. R. Link, P. Laurent-Puig, A. D. Griffiths and V. Taly: Lab. Chip. 11 (2011) 2156.

19 Q. Zhong, S. Bhattacharya, S. Kotsopoulos, J. Olson, V. Taly, A. D. Griffiths, D. R. Linkan and J. W. Larson: Lab. Chip. 11 (2011) 2167.

20 B. J. Hindson, K. D. Ness, D. A. Masquelier, P. Belgrader, N. J. Heredia, A. J. Makarewicz, I. J. Bright, M. Y. Lucero, A. L. Hiddessen, T. C. Legler, T. K. Kitano, M. R. Hodel, J. F. Petersen, P. W. Wyatt, E. R. Steenblock, P. H. Shah, L. J. Bousse, C. B. Troup, J. C. Mellen, D. K. Wittmann, N. G. Erndt, T. H. Cauley, R. T. Koehler, A. P. So, S. Dube, K. A. Rose, L. Montesclaros, S. Wang, D. P. Stumbo, S. P. Hodges, S. Romine, F. P. Milanovich, H. E. White, J. F. Regan, G. A. KarlinNeumann, C. M. Hindson, S. Saxonov and B. W. Colston: Anal. Chem. 83 (2011) 8604.

21 J. J. Agresti, E. Antipov, A. R. Abate, K. Ahn, A. C. Rowat, J.-C. Baret, M. Marquez, A. M. Klibanov, A. D. Griffiths and D. A. Weitz: Proc. Natl. Acad. Sci. 107 (2010) 4004.

22 B. Kintses, C. Hein, M. F. Mohamed, M. Fischlechner, F. Courtois, C. Lainé and F. Hollfelder: Chem. Biol. 19 (2012) 1001.

23 D. Daba: J. Phys. Gen. Phys. 5 (1972) 318.

24 S. F. Cogan: Annu. Rev. Biomed. Eng. 10 (2008) 275.

25 S. Banerjee, M. G. C. Kahn and S. S. Wong: Chem.—Eur. J. 9 (2003) 1898.

26 J. H. Shin, G. B. Kim, E. J. Lee, T. An, K. Shin, S. E. Lee, W. Choi, S. Lee, C. Latchoumane, H.-S. Shin and G. Lim: Adv. Healthc. Mater. 3 (2014) 245.

27 T. An, W. Choi, E. Lee, I. Kim, W. Moon and G. Lim: Nanoscale Res. Lett. 6 (2011) 306.

28 J. I. Yeh and H. Shi: Wiley Interdiscip. Rev. Nanomed. Nanobiotechnol. 2 (2010) 176.

29 H. Shi, T. Xia, A. E. Nel and J. I. Yeh: Nanomed. 2 (2007) 599. 